
\title{
CIÊNCIANATURA
}

\section{A influência da distribuição da precipitação pluviométrica na produção agrícola de soja, no município de Tupanciretã/RS, entre os anos de 2014 e 2015}

The influence of rainfall distribution on soybean production in the municipality of Tupanciretã/RS, from 2014 to 2015

Santhiély Laksmi Silva Gomes ${ }^{1}$ e Cássio Arthur Wollmann ${ }^{2}$

${ }^{1}$ Mestranda PPGGEO, Departamento de Geociências, Universidade federal de Santa Maria, Santa Maria/RS, Brasil santhielygeo@gmail.com

${ }^{2}$ Prof. Doutor, Departamento de Geociências, Universidade federal de Santa Maria, Santa Maria/RS, Brasil cassio_geo@yahoo.com.br

\section{Resumo}

O presente trabalho tem por objetivo analisar a influência da distribuição da precipitação pluviométrica no municipio de Tupanciretã/RS na produção agricola de soja, entre os anos de 2014 e 2015. Para o desenvolvimento deste trabalho foram utilizados os dados divulgados diariamente pela Cooperativa Agrícola Tupanciretã - AGROPAN, de oito pluviômetros localizados em pontos estratégicos no municipio. Os dados de produção agrícola foram obtidos em órgãos públicos como Companhia Nacional de Abastecimento - CONAB, Empresa de Assistência Técnica e Extensão Rural do Governo do Estado do Rio Grande do Sul - EMATER/RS, Empresa Brasileira de Pesquisa Agropecuária - EMPRAPA e Instituto Brasileiro de Geografia e Estatística - IBGE. Dessa forma, pode-se dizer que a distribuição espaço-temporal pluviométrica no município de Tupanciretã/RS no periodo analisado foi influenciada por fenômenos e sistemas de circulação atmosférico.

Palavras-chave: Climatologia. Precipitação. Produção agrícola.

\section{Abstract}

The present work has the objective of analyzing the influence of rainfall distribution in Tupanciretã / RS municipality on soybean production between 2014 and 2015. For the development of this work, the data published daily by the Cooperativa Agricola Tupanciretã - AGROPAN, of eight pluviometers located in strategic points in the city. The data of agricultural production were obtained from public agencies such as the National Supply Company - CONAB, the Technical Assistance and Rural Extension Company of the Government of the State of Rio Grande do Sul EMATER / RS, the Brazilian Agricultural Research Corporation - EMPRAPA and the Brazilian Institute of Geography and Statistics - IBGE. Thus, it can be said that the pluviometric space-time distribution in the Tupanciretã / RS municipality in the analyzed period was influenced by phenomena and atmospheric circulation systems.

Keywords: Climatology. Rainfall. Agricultural production. 


\section{Introdução}

A ciência geográfica tem como objeto de estudo as relações entre sociedade e natureza no espaço geográfico. Sabemos que desde os primórdios o clima da Terra esteve sujeito a variações, ordenadas por ciclos longos e curtos, e que as grandes migrações humanas ocorreram motivadas pelos fenômenos climáticos, ocorridos por processos naturais. Desta forma, os estudos climáticos possuem papel muito importante na Geografia.

Entre os elementos climáticos que possuem maior impacto nos setores da sociedade o regime pluviométrico interfere nas atividades agrícolas e dessa forma no meio ambiente e na economia. Assim, o desenvolvimento e crescimento das culturas agrícolas em função da variabilidade temporal e espacial da distribuição das chuvas determinam a aptidão e o manejo adequado do solo para a agricultura.

Dentro do quadro sócio econômico de Tupanciretã/RS, a agricultura historicamente desempenha um papel importante. A quantidade e distribuição das chuvas que precipitam em seu território são alguns dos principais fatores que favorecem o seu bom desempenho, uma vez que essa variável climatológica é a principal fonte de água para o solo, indispensável no processo fotossintético de incorporação de matéria orgânica pela evapotranspiração.

Conhecer e estudar a precipitação pluvial auxilia no planejamento territorial e ambiental do município. Dessa forma, o presente trabalho objetiva analisar a influência da distribuição da precipitação pluviométrica, entre os anos de 2014 e 2015, comparando os resultados obtidos com fenômenos climáticos que possam influenciar a variabilidade da precipitação e os índices de produção agrícola de soja no município.

\section{Materiais e métodos}

Tupanciretã localiza-se entre as coordenadas geográficas $29^{\circ} 4^{\prime} 57^{\prime \prime}$ de latitude Sul e $53^{\circ} 50^{\prime} 13^{\prime \prime}$ longitude Oeste, situado na região Centro Ocidental Rio-grandense (Figura 01).

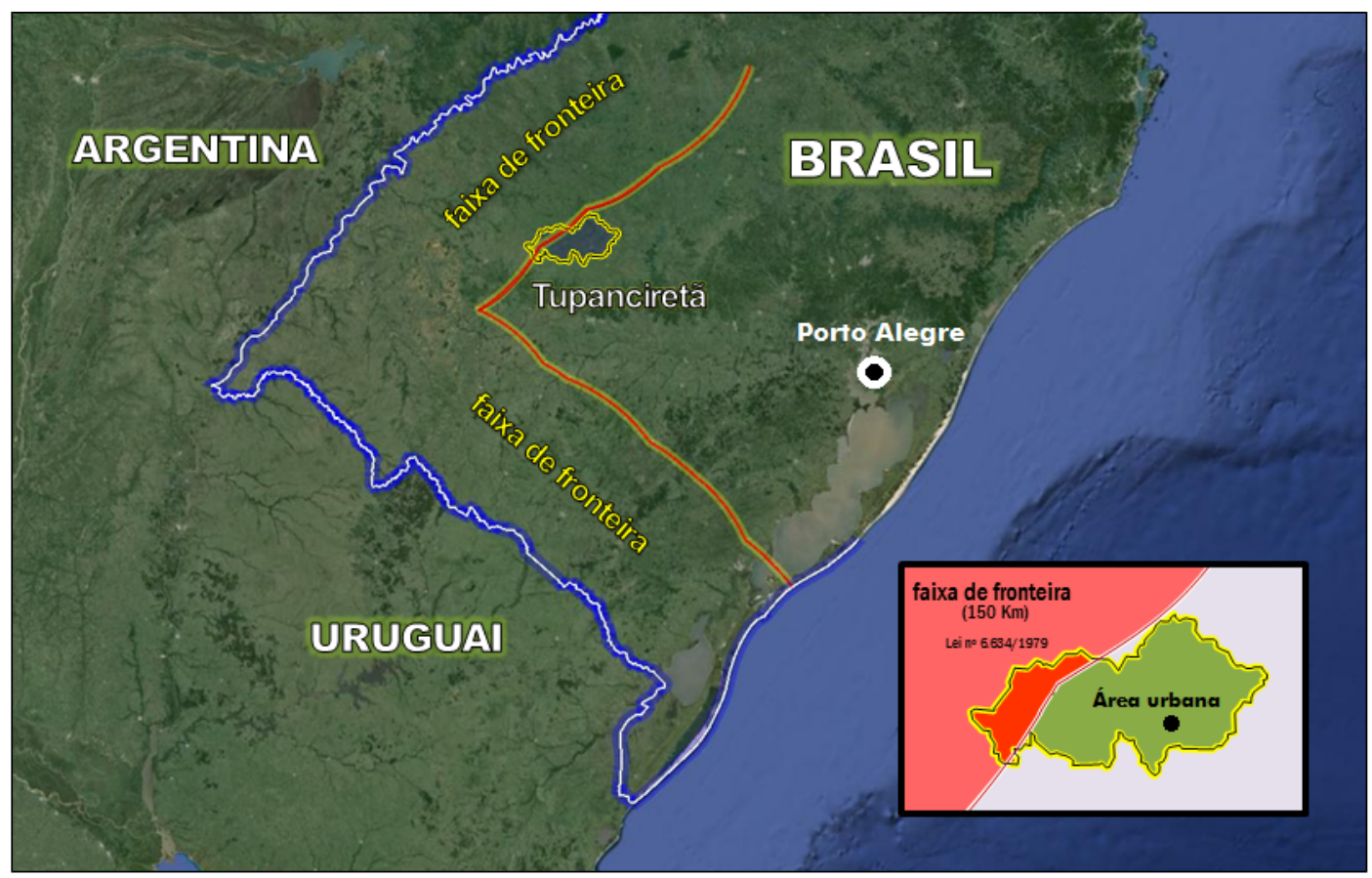

Figura 01 - Localização do município de Tupanciretã. 
Fonte: http://eduardoaugusto-irib.blogspot.com.br/

Apresenta extensão territorial de $2.251,040 \mathrm{~km}^{2}$, sendo que $61,06 \%$ da área territorial é utilizada para a plantação de soja (Instituto de Pesquisa Econômica Aplicada - IPEA, 2010), possui população bruta de 22.281 habitantes (Censo IBGE, 2010), sendo 18.025 habitantes da área urbana (80,90\% do total), e 4.261 habitantes da área rural $(19,10 \%$ do total). Dentro do quadro sócio econômico de Tupanciretã, município com maior índice de produtividade de soja por hectare do Estado e $37^{\circ}$ no país nos últimos anos (Instituto de Pesquisa Econômica Aplicada IPEA, 2017), a agricultura historicamente desempenha um papel importante.

Sua geomorfologia encontra-se na zona de transição compreendida pelo Planalto Dissecado do Rio Uruguai e Escarpa da Serra Geral, e situa-se sobre duas regiões hidrográficas da Bacia do Rio Uruguai (Sub-bacias do Ibicuí e Ijuí) e Bacia Hidrográfica do Lago Guaíba (Sub-bacia do Jacuí). A vegetação predominante nesta área de estudo é constituída por campos nativos, porém, com a exploração antrópica da área, principalmente pelos cultivos agrícolas de soja, trigo e milho, e com o cultivo de gramíneas para pastagens, a vegetação original encontra-se enfraquecida e modificada. Do ponto de vista socioeconômico o município concentra maior parte de seu Produto Interno Bruto (PIB) nas atividades agropecuárias.

Para o desenvolvimento deste trabalho foram utilizados os dados de precipitação divulgados diariamente pela Cooperativa Agrícola Tupanciretã - AGROPAN, de nove pluviômetros localizados em pontos estratégicos no município.

Tabela 1 - Pontos coletados no município de Tupanciretã/RS

\begin{tabular}{l|l|l}
\hline Ponto & Latitude & Longitude \\
\hline Abacatu & $22^{\circ} 81^{\prime \prime} 89^{\prime \prime}$ & $67^{\circ} 75^{\prime \prime} 27^{\prime}$ \\
\hline Bocaverá & $21^{\circ} 26^{\prime \prime} 62^{\prime}$ & $67^{\circ} 87^{\prime \prime} 31^{\prime}$ \\
\hline Caneleira & $21^{\circ} 85^{\prime \prime} 06^{\prime}$ & $67^{\circ} 78^{\prime \prime} 98^{\prime}$ \\
\hline Espinilho & $67^{\circ} 94^{\prime \prime} 42^{\prime}$ & $76^{\circ} 47^{\prime \prime} 70^{\prime}$ \\
\hline Lageado do Celso & $21^{\circ} 12^{\prime \prime} 06^{\prime}$ & $67^{\circ} 74^{\prime \prime} 31^{\prime}$ \\
\hline Santa Tecla & $68^{\circ} 00^{\prime \prime} 90^{\prime}$ & $77^{\circ} 87^{\prime \prime} 40^{\prime}$ \\
\hline São Bernardo & $20^{\circ} 84^{\prime \prime} 35^{\prime}$ & $67^{\circ} 91^{\prime \prime} 86^{\prime}$ \\
\hline São Xavier & $24^{\circ} 29^{\prime \prime} 59^{\prime}$ & $67^{\circ} 86^{\prime} 90$ \\
\hline Sede & $22^{\circ} 50^{\prime \prime} 42^{\prime}$ & $67^{\circ} 78^{\prime \prime} 80^{\prime}$ \\
\hline
\end{tabular}

Fonte: AGROPAN

Os dados de produção agrícola foram obtidos em órgãos públicos como Companhia Nacional de Abastecimento - CONAB, Empresa de Assistência Técnica e Extensão Rural do Governo do Estado do Rio Grande do Sul - EMATER/RS, Empresa Brasileira de Pesquisa Agropecuária - EMPRAPA e Instituto Brasileiro de Geografia e Estatística - IBGE. Após a obtenção dos dados, os mesmos foram manipulados em tabelas no Excel versão 2013, das quais foram selecionados para a análise os dados pluviométricos de Tupanciretã/RS entre 2014 e 2015, e a área colhida, produção por tonelada e rendimento médio da cultura da soja para o período estudado, no qual se analisou a influência dos eventos climáticos na produtividade agrícola, buscando verificar a interferência positiva ou negativa do clima sobre a produtividade agrícola a partir da precipitação. 


\section{Processos Metodológicos}

Conforme Mendonça (1996, p. 46) um dos mais antigos métodos de estudos da Geografia física é a paisagem. Bertrand (1971) aponta a relação dos elementos físicos, biológicos e antrópicos na construção de uma paisagem dinâmica, que implica da participação humana para mudanças.

Após a década de 1970 as mudanças na paisagem rural foram mais intensas, o processo produtivo passou a ser intensivo, houve a introdução de culturas temporárias, voltadas especialmente ao setor de exportação. A partir desse novo modelo de produção, os tipos de cultivo que se destacaram no município de Tupanciretã foram o soja, o trigo e o milho. Mas, especialmente a soja, se adaptou melhor às condições geofisiologica da região, também sendo uma das mais importantes culturas na economia mundial.

A Empresa Brasileira de Pesquisa Agropecuária (EMBRAPA, 2017) destaca a soja como "um grão muito versátil que dá origem a produtos e subprodutos muito usados pela agroindústria, indústria química e de alimentos". Assim o grão apresenta diferentes usos na alimentação humana e animal, nas indústrias e recentemente também vem crescendo como fonte alternativa de combustível, o biodiesel.

Segundo Yokoo (2007. p.30), "para a obtenção de produções econômicas da soja, devem ser atendidas as exigências bioclimáticas básicas: térmicas fotoperiódicas e hídricas”. O cultivo da soja no município se dá entre os meses de outubro e maio, onde as exigências fotoperiódicas, térmica e hídrica são ideais.

\footnotetext{
A disponibilidade de água é importante, principalmente, em dois períodos de desenvolvimento da soja: germinação-emergência e floração enchimento de grãos. Durante o primeiro período, tanto o excesso quanto o déficit de água são prejudiciais à obtenção de uma boa uniformidade na população de plantas. A semente de soja necessita absorver, no mínimo, $50 \%$ de seu peso em água para assegurar boa germinação. Nessa fase, o conteúdo de água no solo não deve exceder a $85 \%$ do total máximo de água disponível e nem ser inferior a 50\%. [...] Sempre que possível, a semeadura da soja não deve ser realizada quando a temperatura do solo estiver abaixo de $20^{\circ} \mathrm{C}$ porque prejudica a germinação e a emergência. A faixa de temperatura do solo adequada para semeadura varia de $20^{\circ} \mathrm{C}$ a $30^{\circ} \mathrm{C}$, sendo $25^{\circ} \mathrm{C}$ a temperatura ideal para uma emergência rápida e uniforme. (EMBRAPA, 2013, p.11-12).
}

Assim a exemplo da soja, as culturas agrícolas são dependentes das condições climáticas de elementos como a temperatura e a precipitação, para uma boa produtividade, necessária ao desenvolvimento da agricultura importante para a economia agrícola da região. Quando buscamos analisar os dados de precipitação junto aos dados de produção entende-se que a precipitação pluviométrica irá influenciar na produção, na qual a umidade do solo vai ser importante para todo o ciclo de desenvolvimento do cultivo, com isso a observação também foi feita no mês que antecede o plantio.

Conforme a figura 02 pode-se observar o total pluviométrico médio entre os nove pluviômetros da AGROPAN em Tupanciretã, para o calendário agrícola da soja de setembro de 2014 a maio de 2015.

Constatou-se que a influência climática na produção agrícola no município de Tupanciretã tem demonstrado suscetibilidade, aos agentes pluviométricos. No ano da safra estudada 2014/2015, precipitou um total médio de 1833,3 mm entre setembro de 2014 e maio de 2015, e a produtividade da soja por hectare foi cerca de 3,0 toneladas por hectare, o que é a produtividade média esperada. Essa expectativa atingida deu-se principalmente devido no período de plantio, que ocorre no mês de outubro, ter apresentado índice pluviométrico satisfatório, bem como em setembro, mês que antecede o plantio. No período de colheita, entre os meses de abril e maio, os índices pluviométricos encontraram-se em valores já acima dos $1500 \mathrm{~mm}$ totais. Neste sentido, fica constatado que as anormalidades climáticas interferem tanto negativa quanto positivamente, no plantio, ou na colheita, testificando a vulnerabilidade da agricultura mediante ao clima. 


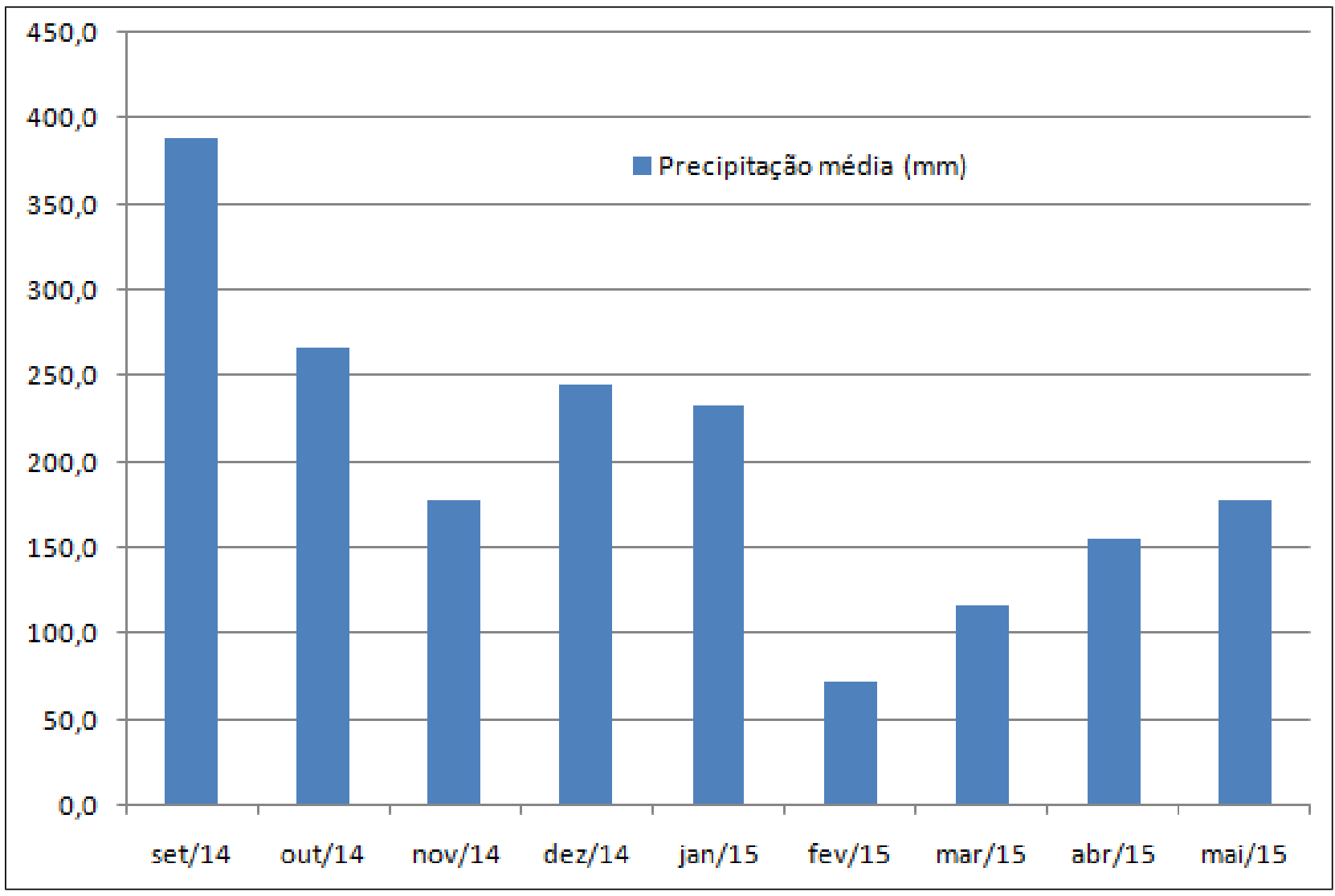

Figura 02 - Total pluviométrico médio entre os nove pluviômetros da AGROPAN em Tupanciretã, para o calendário agrícola da soja de setembro de 2014 a maio de 2015.

Fonte: AGROPAN

\section{Conclusões}

Dessa forma, pode-se dizer que a distribuição espaço-temporal pluviométrica no município de Tupanciretã no período analisado foi influenciada por fenômenos e sistemas de circulação atmosférica, possibilitando um bom ano para o cultivo da soja.

Na análise da distribuição espacial da precipitação pluviométrica no período da safra 2014/2015 podese observar que os meses com os maiores totais pluviométricos foram aqueles cuja planta apresentava maior necessidade, sendo em setembro e outubro de 2014 e no período da colheita a chuva ocorreu, em índices mais baixos, o que auxiliou para que a colheita fosse realizada com sucesso. Visando a importância da climatologia e a análise da precipitação para o cultivo do grão, observou-se sua relevância para os diversos setores da sociedade, principalmente o econômico.

\section{Agradecimentos}

O presente trabalho foi realizado com apoio do Programa Nacional de Cooperação Acadêmica da Coordenação de Aperfeiçoamento de Pessoal de Nível Superior - CAPES/Brasil - N ${ }^{o}$ Processo: 88881.068465/2014/01 - Projeto ${ }^{\circ}$ 071/2013 CAPES/PROCAD. 


\section{Referências}

BERTRAND, G. Paisagem e geografia global: esboço metodológico. Caderno Ciências da Terra, IGEOG-USP, São Paulo: V.13, p.1 - 27, 1972.

COMPANHIA NACIONAL DE ABASTECIMENTO (CONAB). Levantamentos de safra. Disponível em $<$ http://www.conab.gov.br/conteudos.php?a=1253>, acesso em: abril de 2017.

COMPANHIA NACIONAL DE ABASTECIMENTO. Acompanhamento da safra brasileira de grãos. - v. 1, n.3 (2013) - Brasília : Conab, 2013

EMPRESA DE ASSISTÊNCIA TÉCNICA E EXTENSÃO RURAL DO GOVERNO DO ESTADO DO RIO GRANDE DO SUL (EMATER/RS). Disponível em $<$ http://www.emater.tche.br/site/area-tecnica/sistema-deproducao-vegetal>, acesso em: abril de 2017.

EMPRESA BRASILEIRA DE PESQUISA AGROPECUÁRIA (EMBRAPA). Produtos, Processos e Serviços soluções tecnológicas. Disponível em < https:/www.embrapa.br/produtos-processos-e-servicosacesso em: abril de 2017.

INSTITUTO BRASILEIRO DE GEOGRAFIA E ESTATÍSTICA (IBGE). Dados Demográficos Censo 2010. IBGE, 2014. Disponível em <www.ibge.gov.br>, acesso em: abril de 2017.

INSTITUTO DE PESQUISA ECONÔMICA APLICADA $\quad$ (IPEA). Disponível em < http://www.ipeadata.gov.br/Default.aspx>, acesso em: abril de 2017.

MENDONÇA Francisco de Assis. Geografia física: ciência humana?. 4. ed. São Paulo: Contexto, 1996.

Tecnologias de produção de soja - Região Central do Brasil 2014. - Londrina: Embrapa Soja, 2013.

YOKOO, S. C. Anos bons e anos ruins, do ponto de vista climático, para as culturas do trigo e da soja no município de Campo Mourão-PR. 2007. 171 f. Dissertação (Mestrado em Geografia) - Centro de Ciências Humanas, Letras e Artes, Universidade Estadual de Maringá, Maringá. 2007 